\title{
miR-128 Targets the SIRT1/ROS/DR5 Pathway to Sensitize Colorectal Cancer to TRAIL-Induced Apoptosis
}

\author{
Bo Lian ${ }^{\mathrm{a}}$ Dongxiang Yang ${ }^{\mathrm{b}}$ Yanlong Liuc Gang Shi ${ }^{\mathrm{a}}$ Jibin $\mathrm{Li}^{\mathrm{a}}$ \\ Xiaofei Yana Keer Jin ${ }^{a} \quad$ Xin Liu $^{\mathrm{a}}$ Jianfeng Zhao ${ }^{\mathrm{a}}$ Wen Shang ${ }^{\mathrm{a}}$ \\ Rui Zhanga
}

aDepartment of Colorectal Surgery, Cancer Hospital of China Medical University, Liaoning Cancer Hospital and Institute, Shenyang, 'Department of Orthopedics, The Affiliated Hospital of Liaoning University of Traditional Chinese Medicine, Shenyang, 'Department of Colorectal Surgery, Harbin Medical University Cancer Hospital, Harbin, China

\section{Key Words \\ miR-128 • TRAIL $・$ SIRT1 $・$ ROS $・$ DR5}

\begin{abstract}
Background/Aims: Tumor necrosis factor-related apoptosis-inducing ligand (TRAIL) is an ideal anti-tumor drug because it exhibits selective cytotoxicity against cancer cells. However, certain cancer cells are resistant to TRAIL, and the potential mechanisms are still unclear. The aim of this study was to reduce the resistance of colorectal cancer (CRC) cells to TRAIL. Methods: Quantitative real-time PCR analysis was performed to detect the expression of microRNA-128 (miR-128) in tissues from patients with CRC and CRC cell lines. MTT assays were used to evaluate the effect of miR-128 on TRAIL-induced cytotoxicity against CRC cell lines. The distribution of death receptor 5 (DR5) and the production of reactive oxygen species (ROS) were detected by flow cytometry analysis. Western blot, flow cytometry, and luciferase reporter assays were performed to evaluate the potential mechanism and pathway of miR-128-promoted apoptosis in TRAIL-treated CRC cells. Results: MiR-128 expression was downregulated in tumor tissues from patients with CRC as well as in CRC cell lines in vitro. The enforced expression of miR-128 sensitized CRC cells to TRAIL-induced cytotoxicity by inducing apoptosis. Mechanistically, bioinformatics, western blot analysis, and luciferase reporter assays showed that miR-128 directly targeted sirtuin 1 (SIRT1) in CRC cells. miR128 overexpression suppressed SIRT1 expression, which promoted the production of ROS in TRAIL-treated CRC cells. This increase of ROS subsequently induced DR5 expression, and thus increased TRAIL-induced apoptosis in CRC cells. Conclusion: The combination of miR-128 with TRAIL may represent a novel approach for the treatment of CRC.
\end{abstract}




\section{Introduction}

Due to the high incidence of liver metastasis, colorectal cancer (CRC) has a poor prognosis and represents one of the leading causes of cancer-related deaths worldwide $[1,2]$. For patients with CRC, especially early-stage patients, surgical resection followed by chemotherapy represents the standard current treatment $[3,4]$. However, the clinical use of chemotherapeutic drugs usually induces severe side-effects because continuous chemotherapy is inevitably toxic to normal tissues. Furthermore, chemoresistance is still a major obstacle for the provision of effective treatment to many patients with CRC [5, 6]. Given this, it is urgent to explore novel strategies to overcome the problems of drug resistance and toxicity.

Tumor necrosis factor-related apoptosis-inducing ligand (TRAIL) is an anti-tumor cytokine that belongs to the tumor necrosis factor superfamily. TRAIL binds to death receptors 5 (DR5) located on the surface of cancer cells, and thus activates caspase-8dependent apoptosis [7-9]. By contrast, treatment with TRAIL has no effect on normal tissues [10]. Therefore, TRAIL is considered as an ideal anti-tumor drug that exhibits selective cytotoxicity against cancer cells. Given that certain cancer cells are resistant to TRAIL [11, 12], we explored novel strategies to increase the sensitivity of CRC cells to TRAIL.

MicroRNAs (miRNAs) are endogenous small, non-coding RNAs that suppress gene expression by partially pairing with the $3^{\prime}$ untranslated region (3'-UTR) of targeted mRNAs. MiRNAs have been observed to be dysregulated in almost all human cancers $[13,14]$. Correcting the aberrant expression of miRNAs has been shown to inhibit cell proliferation, metastasis, invasion, and chemoresistance in cancers $[15,16]$. As recent studies have demonstrated the association between the miRNA expression profile and TRAIL sensitivity in some cancers $[17,18]$, we aimed to explore the ability of the combination of TRAIL with miR-128 to enhance TRAIL-induced cytotoxicity against CRC.

\section{Materials and Methods}

\section{Cell lines and tissue samples}

The human CRC cell lines HT29, SW480, and SW620 and the human normal colon cell line FHC were purchased from the American Type Culture Collection (Manassas, VA). The cells were cultured in Dulbecco's modified Eagle's medium (Gibco, Gaithersburg, MD) with $10 \%$ fetal bovine serum (Gibco) at $37{ }^{\circ} \mathrm{C}$ in a humidified incubator with $5 \% \mathrm{CO}_{2}$. Tumor tissues and their corresponding paracancerous tissues were obtained from 30 patients with primary CRC at the Cancer Hospital of China Medical University, Liaoning Cancer Hospital and Institute. We obtained informed consent from all patients, and the experimental protocols were approved by the ethics committee of the Cancer Hospital of China Medical University, Liaoning Cancer Hospital and Institute.

\section{Quantitative real-time polymerase chain reaction}

The relative expression of miR-128 and sirtuin 1 (SIRT1) was detected by quantitative real-time PCR (qRT-PCR) on an Applied Biosystems ABI Prism 7900 sequence detection system (Applied Biosystems, Foster City, CA). Briefly, total RNA was extracted with the TRIzol reagent (Invitrogen, Carlsbad, CA). Subsequently, reverse transcription of RNA was performed by using a One Step PrimeScript miRNA cDNA Synthesis Kit (Takara Biotechnology (Dalian) Co., Ltd., Dalian, China) followed by real-time PCR amplification with SYBR Premix Ex Taq (Takara Biotechnology (Dalian) Co., Ltd.). The relative expression of miR-128 and SIRT1 was analyzed by the $2^{-\triangle \Delta C T}$ method and normalized to U6 snRNA and GAPDH, respectively.

\section{Cell transfection}

Hsa-miR-128 (5'-UCACAGUGAACCGGUCUCUUU-3') and negative control sequence (miR-NC, 5'-AUCAAUUGGUCUCAGUCGUCC-3') were purchased from Genechem Co., Ltd. (Shanghai, China). SIRT1 small interfering RNA (siRNA) was purchased from Santa Cruz (Santa Cruz, CA). A SIRT1 expression vector was generated by cloning the open reading frame of the SIRT1 gene into the pcDNA3.1 plasmid. The cells

\section{KARGER}




\section{Cellular Physiology Cell Physiol Biochem 2018;49:2151-2162

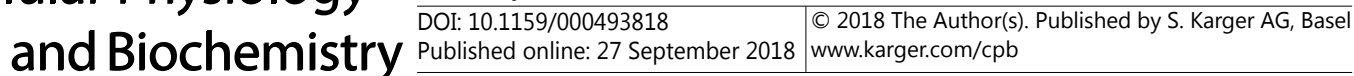 \\ Lian et al.: miR-128 Sensitizes CRC to TRAIL}

were transfected with miR-128 or miR-NC (50 pmol/mL), SIRT1 plasmid ( $2 \mu \mathrm{g} / \mathrm{mL})$, or siRNA (50 pmol/ $\mathrm{mL}$ ) by using the Lipofectamine 2000 reagent (Invitrogen) according to the manufacturer's instructions.

\section{Cell viability}

Transfected cells were seeded into 96-well plates at a density of $5.0 \times 10^{3}$ cells/well and cultured at 37 ${ }^{\circ} \mathrm{C}$. After adherence to the plate, the cells were treated with TRAIL (0-30 ng/mL; R\&D Systems, Minneapolis, $\mathrm{MN}$ ) for $48 \mathrm{~h}$. To measure cell viability, $20 \mu \mathrm{L}$ MTT reagent ( $5 \mathrm{mg} / \mathrm{mL}$; Sigma-Aldrich, St. Louis, M0) was added to the culture medium and the cells were incubated for $4 \mathrm{~h}$ at $37^{\circ} \mathrm{C}$ in a humidified incubator with $5 \%$ $\mathrm{CO}_{2}$. The cells were then suspended in $150 \mu \mathrm{L}$ dimethyl sulfoxide followed by detection of the absorbance at $570 \mathrm{~nm}$ on an enzyme-linked immunosorbent assay microplate reader (Sunrise Microplate Reader; TECAN, Männedorf, Switzerland).

\section{Luciferase assays}

The 3 '-UTR of SIRT1 containing a putative complementary binding site for miR-128 was synthesized and cloned into the pmiR luciferase reporter (Invitrogen) downstream of the luciferase gene, and designated as the "pmiR-wild SIRT1" plasmid. A "pmiR-mutant SIRT1" plasmid was created by using a site-directed mutagenesis kit (Takara Bio Inc., Kusatsu, Japan). For luciferase assays, the cells were co-transfected with miR-128 (50 pmol/mL) or miR-NC (50 pmol/mL) and reporter plasmids. At $48 \mathrm{~h}$ post-transfection, firefly and Renilla luciferase activity was measured consecutively by using a Dual-Luciferase Reporter System Kit (Promega, Madison, WI) according to the manufacturer's protocol. Relative luciferase activity in the miR128 groups was expressed as a firefly/Renilla luciferase ratio and normalized to the miR-NC groups.

\section{Western blot analysis}

Total protein was extracted by lysing the cells in RIPA buffer (Cell Signaling Technology, Danvers, MA). Equal amounts of protein were separated by $10 \%$ sodium dodecyl sulfate-polyacrylamide gel electrophoresis and transferred to a polyvinylidene fluoride membrane (Millipore, Billerica, MA). Subsequently, the membrane was blocked in $5 \%$ skimmed milk before being probed with primary antibodies. Next, the primary antibody-incubated membrane was probed with a suitable horseradish peroxidase-conjugated secondary antibody for $2 \mathrm{~h}$. The blot was then visualized by using an enhanced chemiluminescence detection kit (Pierce Biotechnology, Waltham, MA). In addition, to detect the protein level of truncated Bid (tBid) in mitochondria, a Mitochondria/Cytosol Fraction Kit (BioVision, Milpitas, CA) was used to separate mitochondria from the cytoplasm.

\section{Flow cytometry analysis}

DR5, apoptosis, reactive oxygen species (ROS) generation, and mitochondrial membrane potential $(\Delta \varphi)$ were detected by flow cytometry analyses. To detect DR5 on the cell surface, the cells were incubated with an anti-DR5-PE antibody (R\&D Systems) followed by analysis on a flow cytometer (Becton Dickinson, USA). To evaluate cell apoptosis, annexinV-positive (Sigma-Aldrich) cells were measured by flow cytometry. To detect ROS production, the cells were incubated with dihydroethidium (Molecular Probes, Eugene, OR) according to the manufacturer's instructions before analysis on a flow cytometer. To measure $\Delta \varphi$, the cells were stained with 5, 5',6, 6' -tetrachloro-1, 1',3, 3'-tetraethylbenzimidazoly-lcarbocyanine iodide (Molecular Probes) and red fluorescence was detected by flow cytometry.

\section{Statistical analysis}

The experiments were repeated independently at least 3 times to obtain the data. Statistical analysis was performed by analysis of variance methods using SPSS 15.0 software (SPSS Inc., Chicago, IL). Differences were considered statistically significant for $P$-values $<0.05$. 


\section{Results}

\section{Dysregulation of miR-128 in CRC}

To investigate the potential role of miR-128 in CRC, we examined its expression levels in CRC cells in vivo and in vitro. In CRC patients, we observed a significant decrease of miR128 expression in tumor tissues compared to their corresponding paracancerous tissues (Fig. 1A). In CRC cell lines, we found that miR-128 expression was clearly lower in the HT29, SW480, and SW620 CRC cell lines than in the FHC normal colon cell line (Fig. 1B). Taken together, these results demonstrated the dysregulation of miR-128 expression in CRC.

\section{miR-128 sensitizes CRC cells to TRAIL-induced cytotoxicity}

To investigate the association between miR-128 dysregulation and TRAIL resistance in CRC, we restored the expression of miR-128 in HT29, SW480, and SW620 CRC cells by transfection with miR-128 mimics (Fig. 2A). Subsequently, we performed MTT assays to evaluate the sensitivity of these transfected cells to TRAIL. As shown in Fig. 2B, transfection with miR-128 dramatically enhanced the sensitivity of HT29, SW480, and SW620 cells to TRAIL. We thus demonstrated that the recovery of miR-128 expression could sensitize HT29, SW480, and SW620 CRC cells to TRAIL-induced cytotoxicity.

miR-128 promotes TRAIL-dependent apoptosis and upregulation of DR5 in CRC

As the recovery of miR-128 expression was able to augment the death of SW480 cells when they were under low-dose TRAIL treatment $(5 \mathrm{ng} / \mathrm{mL})$, we performed the following experiments to explore the mechanisms of miR-128-promoted cell death in this CRC cell line. TRAIL binds to DR5 and thus triggers apoptotic cell death in cancer cells [7]. As expected, we found that the recovery of miR-128 expression in SW480 cells enhanced TRAIL-induced apoptosis (Fig. 3A). However, we found that single treatment with miR-128 had no effect

Fig. 1. Downregulation of miR-128 in CRC. A: Expression levels of miR128 in 30 primary tumor tissues from patients with CRC and their corresponding paracancerous tissues were tested by qRT-PCR analysis. $* \mathrm{P}<0.05$ vs. paracancerous tissues. B: Expression levels of miR-128 in FHC, HT29, SW480, and SW620 cell lines. $* \mathrm{P}<0.05$ vs. FHC.
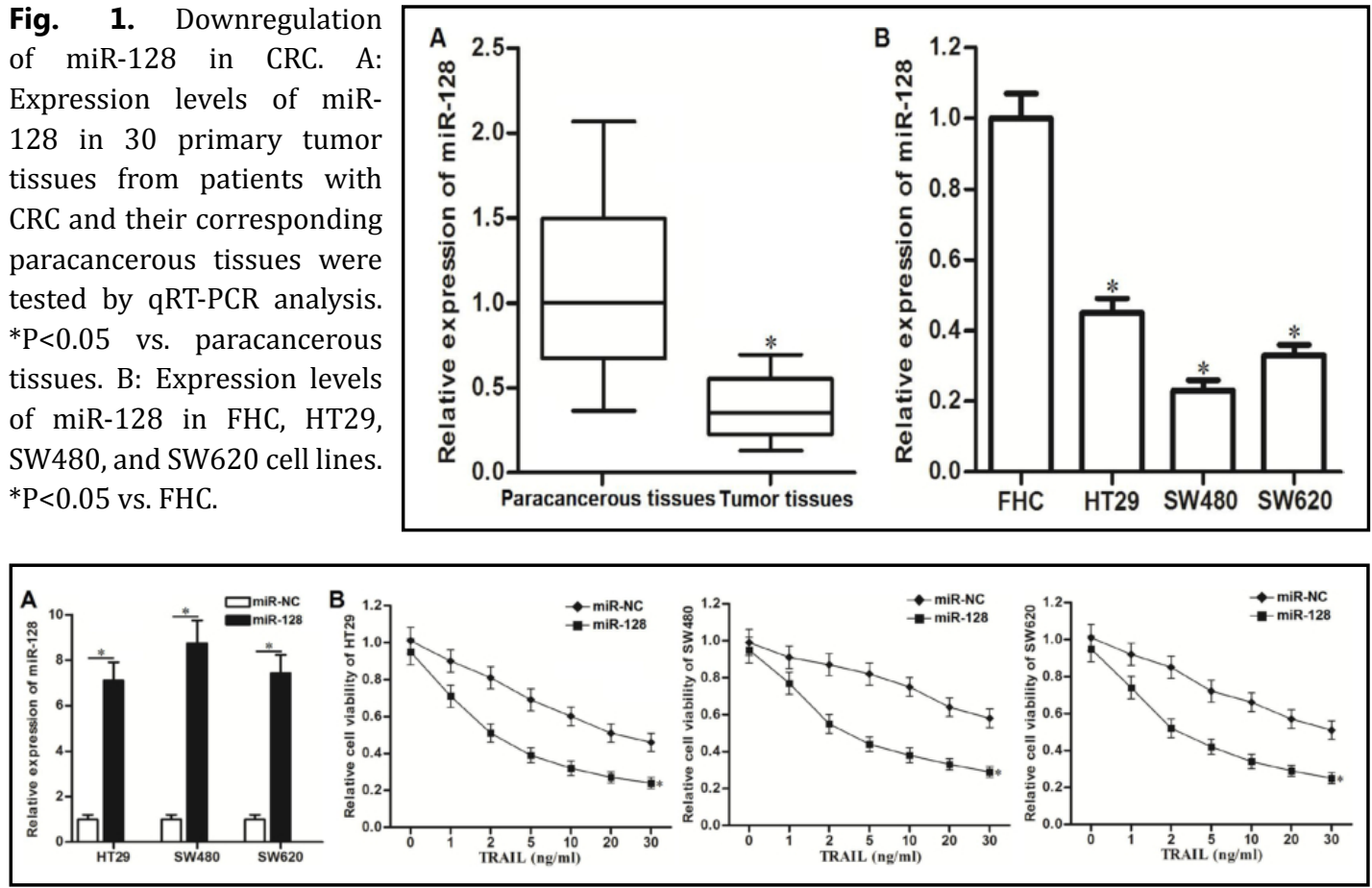

Fig. 2. miR-128 sensitizes CRC cells to TRAIL-induced cytotoxicity. A: Efficiency of miR-128 mimics (50 $\mathrm{pmol} / \mathrm{mL}$ ) to increase the cellular levels of miR-128 in HT29, SW480, and SW620 cells. ${ }^{*} \mathrm{P}<0.05$. B: MTT assays were performed to evaluate the effect of miR-128 (50 pmol/mL) on TRAIL-induced cytotoxicity in HT29, SW480, and SW620 CRC cells. *P<0.05 vs. miR-NC group. 


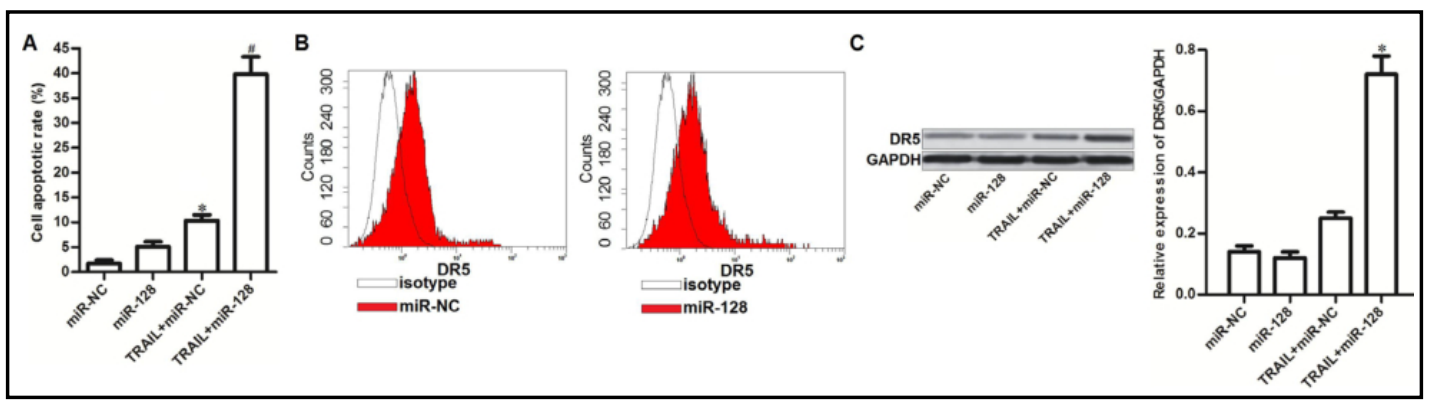

Fig. 3. miR-128 promotes TRAIL-dependent apoptosis and upregulation of DR5. A: Apoptosis of SW480 cells treated with TRAIL ( $5 \mathrm{ng} / \mathrm{mL})$ and miR-128 (50 pmol $/ \mathrm{mL})$ was analyzed by flow cytometry. ${ }^{*} \mathrm{P}<0.05$ vs. miR-NC group; ${ }^{\#} \mathrm{P}<0.05$ vs. TRAIL + miR-NC group. B: DR5 levels on the surface of SW480 cells were detected by flow cytometry analysis after the cells were transfected with miR-128 (50 pmol/mL). C: SW480 cells were treated with TRAIL (5 ng/mL) and miR-128 (50 pmol/mL) followed by western blot analysis of DR5. ${ }^{*} \mathrm{P}<0.05$ vs. TRAIL + miR-NC group.

on the levels of DR5 on the surface of SW480 cells (Fig. 3B). Interestingly, the recovery of miR-128 expression increased the expression of DR5 on SW480 cells when they were under TRAIL treatment (Fig. 3C). Taken together, these results suggested that the combination of miR-128 with TRAIL promoted the TRAIL-dependent upregulation of DR5 expression through an indirect pathway, and thus enhanced TRAIL-induced cell apoptosis in CRC.

\section{miR-128 targets SIRT1 in CRC}

To explore the mechanisms underlying the functions of miR-128 in CRC, we searched for potential mRNA targets of miR-128 by using the public miRNA databases of TargetScan, miRanda, and PicTar. SIRT1 was predicted as a target by all of these predictive tools and contained a complementary site paired with miR-128 (Fig. 4A). Furthermore, SIRT1 was found to be overexpressed at both the mRNA level (Fig. 4B and 4C) and protein level (Fig. 4D) in CRC tissues and cell lines compared with paracancerous tissues and the FHC normal colon cell line, respectively. This suggested a potential negative correlation between SIRT1 expression and miR-128 level in CRC. Next, we found that SIRT1 was decreased in SW480 cells following transfection with miR-128 at both the mRNA and protein level (Fig. 4E and $4 \mathrm{~F}$ ), which indicated that SIRT1 expression was regulated by miR-128. To confirm that miR-128 directly targeted the $3^{\prime}$-UTR of SIRT1, we inserted the $3^{\prime}$-UTR (either wild-type or mutated) of SIRT1 into a pmiR luciferase reporter and co-transfected it with miR-128 mimics. We observed that co-transfection with miR-128 significantly inhibited the luciferase activity of the reporter containing wild-type SIRT1 3'-UTR, but had no effect on the reporter containing the mutant one (Fig. 4G). Taken together, these findings demonstrated that miR128 targeted SIRT1 in CRC.

\section{miR-128 sensitizes CRC cells to TRAIL-induced cytotoxicity by suppressing SIRT1}

To investigate whether miR-128-promoted cell death was dependent on the SIRT1 pathway, we performed gain-of-function and loss-of-function experiments in SW480 cells. Similarly with miR-128, we found that transfection with SIRT1 siRNA significantly decreased the level of SIRT1 protein in TRAIL-treated SW480 cells (Fig. 5A). On the other hand, transfection with the SIRT1-expressing plasmid abolished the inhibition of SIRT1 expression by miR-128 in TRAIL-treated SW480 cells (Fig. 5B). MTT assays showed that SIRT1 knockdown with siRNA significantly sensitized SW480 cells to TRAIL-induced cytotoxicity. The effect of SIRT1 siRNA was similar to that of miR-128 (Fig. 5C). By contrast, the enforced expression of SIRT1 in SW480 cells abolished the effect of miR-128 on sensitizing SW480 cells to TRAIL-induced cytotoxicity (Fig. 5D). Taken together, these results demonstrated that miR-128 sensitized CRC cells to TRAIL-induced cytotoxicity by suppressing the expression of SIRT1.

\section{KARGER}




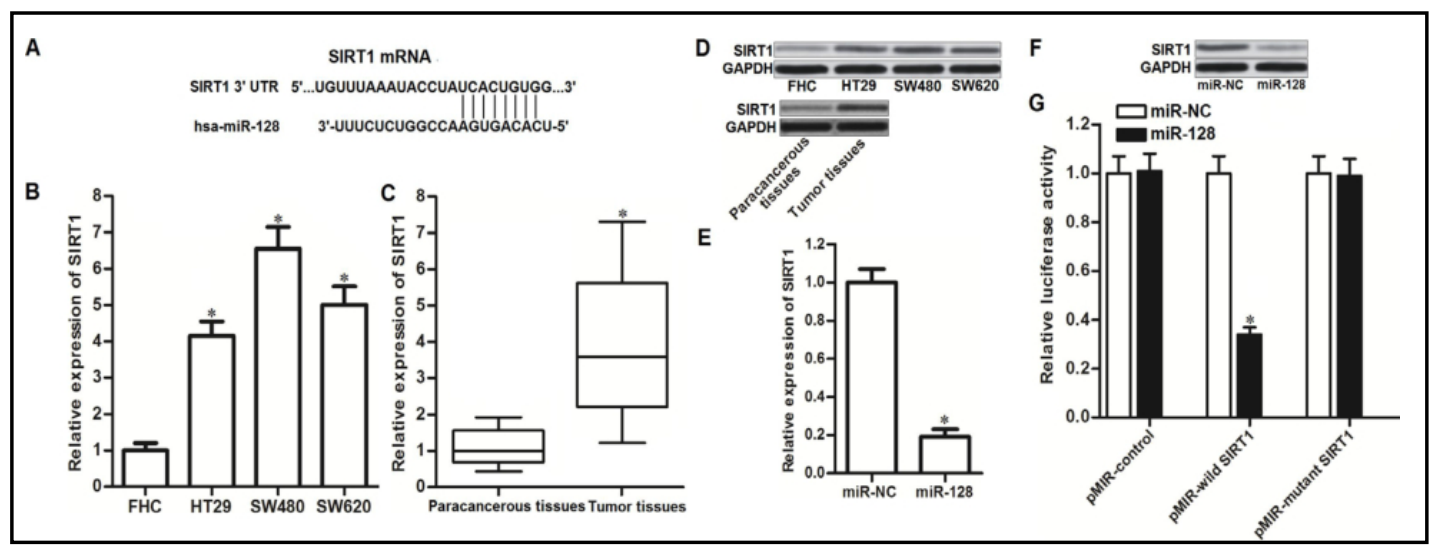

Fig. 4. SIRT1 is a direct target of miR-128. A: Complementary site in the 3 '-UTR of SIRT1 paired with miR128. B: qRT-PCR analysis of SIRT1 mRNA expression in FHC, HT29, SW480, and SW620 cell lines. ${ }^{*} \mathrm{P}<0.05$ vs. FHC cell line. C: qRT-PCR analysis of SIRT1 mRNA expression in tumor and paracancerous tissues from patients with CRC. ${ }^{*} \mathrm{P}<0.05$ vs. paracancerous tissues. D: Western blot analysis of SIRT1 protein expression in tissues from patients with CRC and the FHC, HT29, SW480, and SW620 cell lines. E: qRT-PCR analysis of SIRT1 mRNA expression in SW480 cells transfected with miR-128 (50 pmol/mL). ${ }^{*} \mathrm{P}<0.05$ vs. miR-NC group. F: Western blot analysis of SIRT1 protein expression in SW480 cells transfected with miR-128 (50 $\mathrm{pmol} / \mathrm{mL})$. G: SW480 cells were co-transfected with miR-128 (50 pmol/mL) and pmiR luciferase reporters containing the $3^{\prime}$-UTR of SIRT1. At $48 \mathrm{~h}$ post-transfection, the Dual-Luciferase Reporter Assay System was used to detect relative luciferase activity. ${ }^{*} \mathrm{P}<0.05$ vs. miR-NC group.

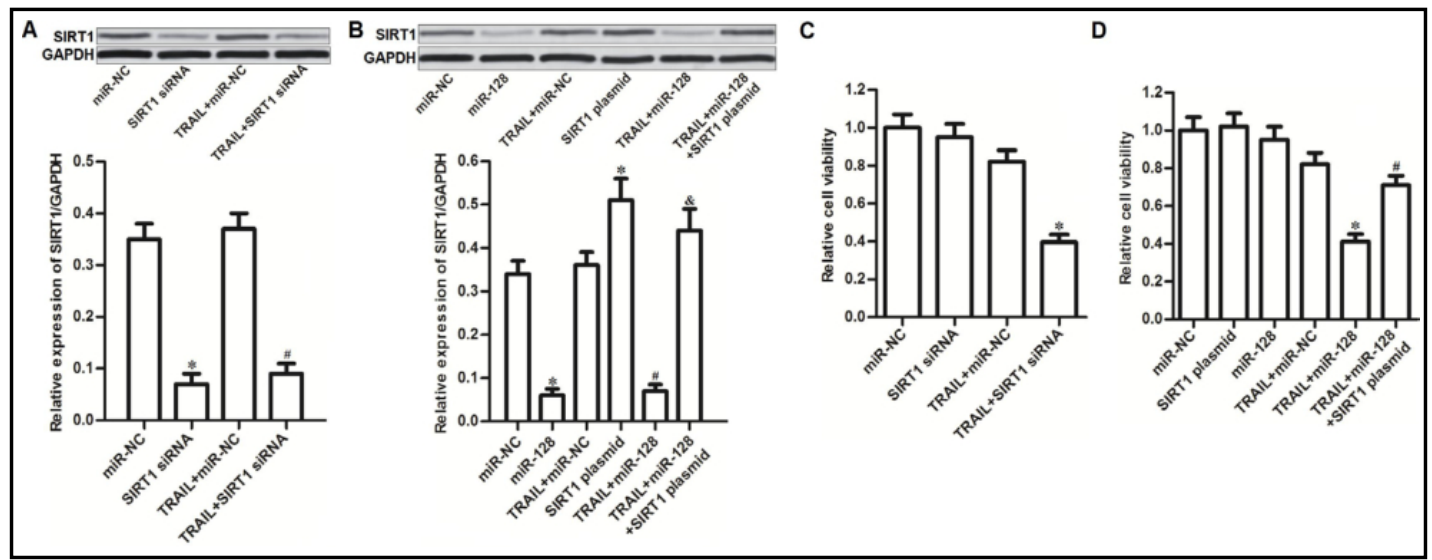

Fig. 5. Role of SIRT1 in miR-128-promoted cell death induced by TRAIL. A: Transfection of SIRT1 siRNA ( $50 \mathrm{pmol} / \mathrm{mL}$ ) was evaluated by western blot analysis in TRAIL-treated ( $5 \mathrm{ng} / \mathrm{mL}$ ) SW480 cells. ${ }^{*} \mathrm{P}<0.05$ vs. miR-NC group; "P<0.05 vs. TRAIL + miR-NC group. B: Transfection of SIRT1 plasmid ( $2 \mu \mathrm{g} / \mathrm{mL})$ in TRAILtreated ( $5 \mathrm{ng} / \mathrm{mL}$ ) SW480 cells. ${ }^{*} \mathrm{P}<0.05$ vs. miR-NC group; ${ }^{~} \mathrm{P}<0.05$ vs. TRAIL + miR-NC group; ${ }^{\circledR} \mathrm{P}<0.05$ vs. TRAIL + miR-128 group. C: Synergistic effect of SIRT1 siRNA (50 pmol/mL) on TRAIL-induced (5 ng/mL) cytotoxicity in SW480 cells. ${ }^{*} \mathrm{P}<0.05$ vs. TRAIL + miR-NC group. D: Effect of the SIRT1 plasmid $(2 \mu \mathrm{g} / \mathrm{mL})$ on protecting SW480 cells co-treated with TRAIL $(5 \mathrm{ng} / \mathrm{mL})$ and miR-128 (50 pmol/mL). $* \mathrm{P}<0.05$ vs. TRAIL + miR-NC group; ${ }^{\text {P }}<0.05$ vs. TRAIL + miR-128 group.

miR-128 sensitizes CRC cells to TRAIL-induced cytotoxicity through the SIRT1/ROS/DR5 pathway

Our preceding results showed that miR-128 promoted the TRAIL-dependent upregulation of DR5 expression through an indirect pathway. We next explored the potential mechanisms by which miR-128 promoted TRAIL-induced cell death in CRC. Flow cytometry analysis showed that single treatment with miR-128 did not induce ROS production in 
SW480 cells. However, the combination of miR-128 with TRAIL enhanced the production of ROS significantly. On the other hand, the miR-128/TRAIL-promoted production of ROS was inhibited by either N-acetylcysteine (NAC), which is an ROS scavenger [19], or the SIRT1 plasmid (Fig. 6A), indicating that miR-128 targeted SIRT1 to enhance the generation of ROS induced by TRAIL in CRC. Western blot analysis showed that the combination of miR-128 with TRAIL clearly increased the expression of DR5 in TRAIL-treated SW480 cells. However, the miR-128-promoted overexpression of DR5 was inhibited by either the SIRT1 plasmid or NAC (Fig. 6B). This indicated that miR-128 promoted the expression of DR5 in TRAILtreated CRC cells indirectly through the SIRT1/ROS pathway. MTT assays showed that the combination of miR-128 with TRAIL induced significant cell death in SW480 cells. However,

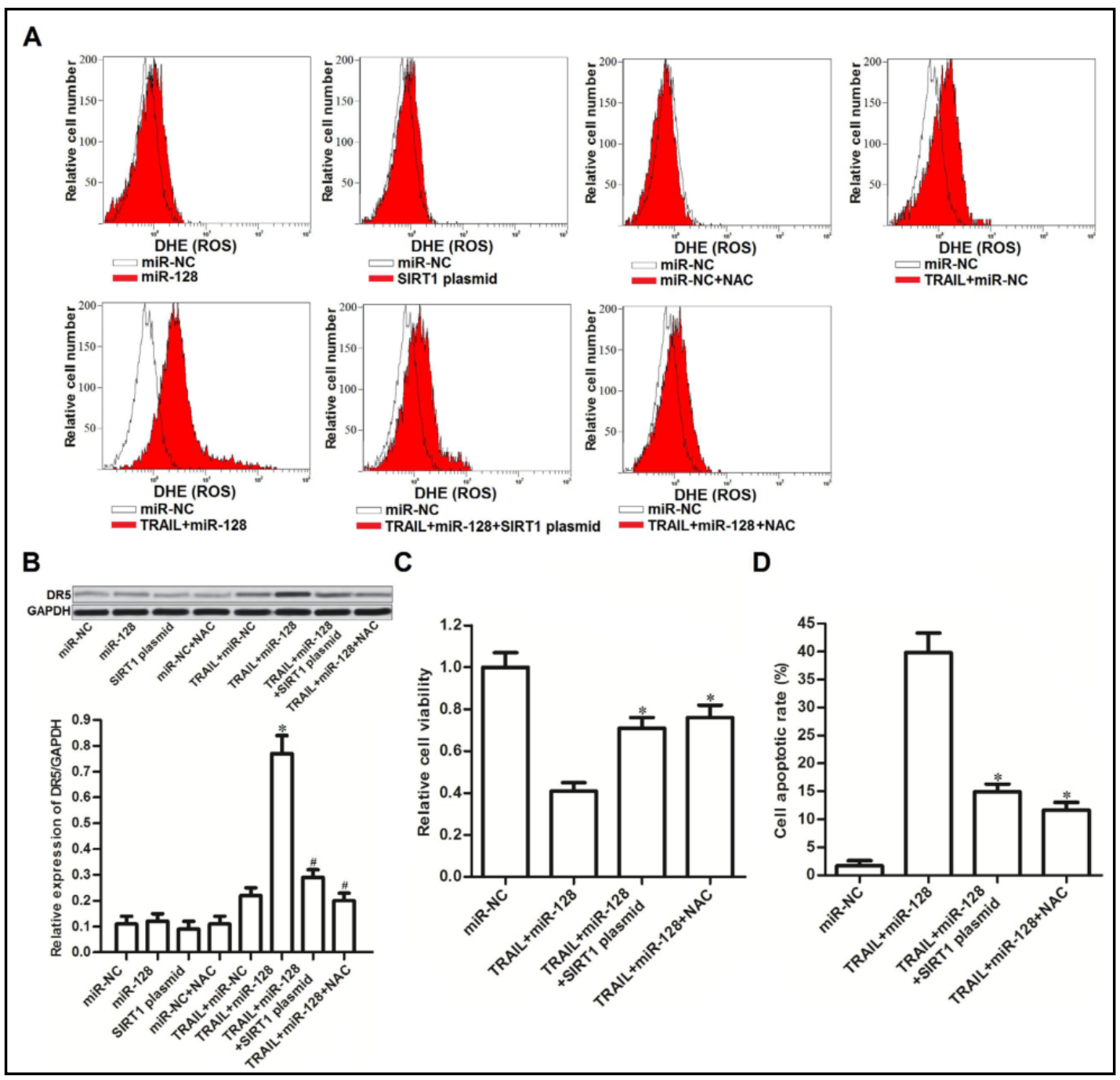

Fig. 6. miR-128 sensitizes CRC cells to TRAIL-induced cytotoxicity through the SIRT1/ROS/DR5 pathway. A: Flow cytometry analysis was performed to detected ROS production in SW480 cells treated with TRAIL (5 $\mathrm{ng} / \mathrm{mL})$, miR-128 (50 pmol/mL), SIRT1 plasmid ( $2 \mu \mathrm{g} / \mathrm{mL})$, and NAC (2 mM). B: Western blot analysis was performed to evaluate DR5 expression in SW480 cells treated with TRAIL (5 ng/mL), miR-128 (50 pmol/ $\mathrm{mL})$, SIRT1 plasmid $(2 \mu \mathrm{g} / \mathrm{mL})$, and NAC $(2 \mathrm{mM}) .{ }^{*} \mathrm{P}<0.05$ vs. TRAIL + miR-NC group; ${ }^{\#} \mathrm{P}<0.05$ vs. TRAIL + miR-128 group. C: Effect of the SIRT1 plasmid ( $2 \mu \mathrm{g} / \mathrm{mL})$ and NAC ( $2 \mathrm{mM})$ on inhibiting the death of SW480 cells co-treated with TRAIL ( $5 \mathrm{ng} / \mathrm{mL})$ and miR-128 $(50 \mathrm{pmol} / \mathrm{mL}) .{ }^{*} \mathrm{P}<0.05 \mathrm{vs}$. TRAIL + miR-128 group. D: Effect of the SIRT1 plasmid ( $2 \mu \mathrm{g} / \mathrm{mL})$ and NAC (2 mM) on inhibiting the apoptosis of SW480 cells cotreated with TRAIL $(5 \mathrm{ng} / \mathrm{mL})$ and miR-128 $(50 \mathrm{pmol} / \mathrm{mL}) .{ }^{*} \mathrm{P}<0.05 \mathrm{vs}$. TRAIL + miR-128 group. 
the SIRT1 plasmid or NAC protected SW480 cells from the cytotoxicity of TRAIL and miR128 co-treatment (Fig. 6C). In addition, the SIRT1 plasmid or NAC inhibited the apoptosis of SW480 cells co-treated with TRAIL and miR-128 (Fig. 6D). Taken together, we demonstrated that miR-128 sensitized CRC cells to TRAIL-induced cytotoxicity through the SIRT1/ROS/ DR5 pathway.

\section{miR-128 promotes TRAIL-induced mitochondrial apoptosis in CRC}

We next investigated the effect of miR-128 on the TRAIL signaling pathway in CRC. As the conjugation of TRAIL and DR5 initiates caspase-8-dependent apoptosis [16], we first evaluated the effect of miR-128 on the TRAIL-induced activation of caspase-8 in SW480 cells. As shown in Fig. 7A, the combination of miR-128 with TRAIL clearly increased the cleavage of caspase-8. However, the SIRT1 plasmid or NAC inhibited caspase-8 activation in TRAIL

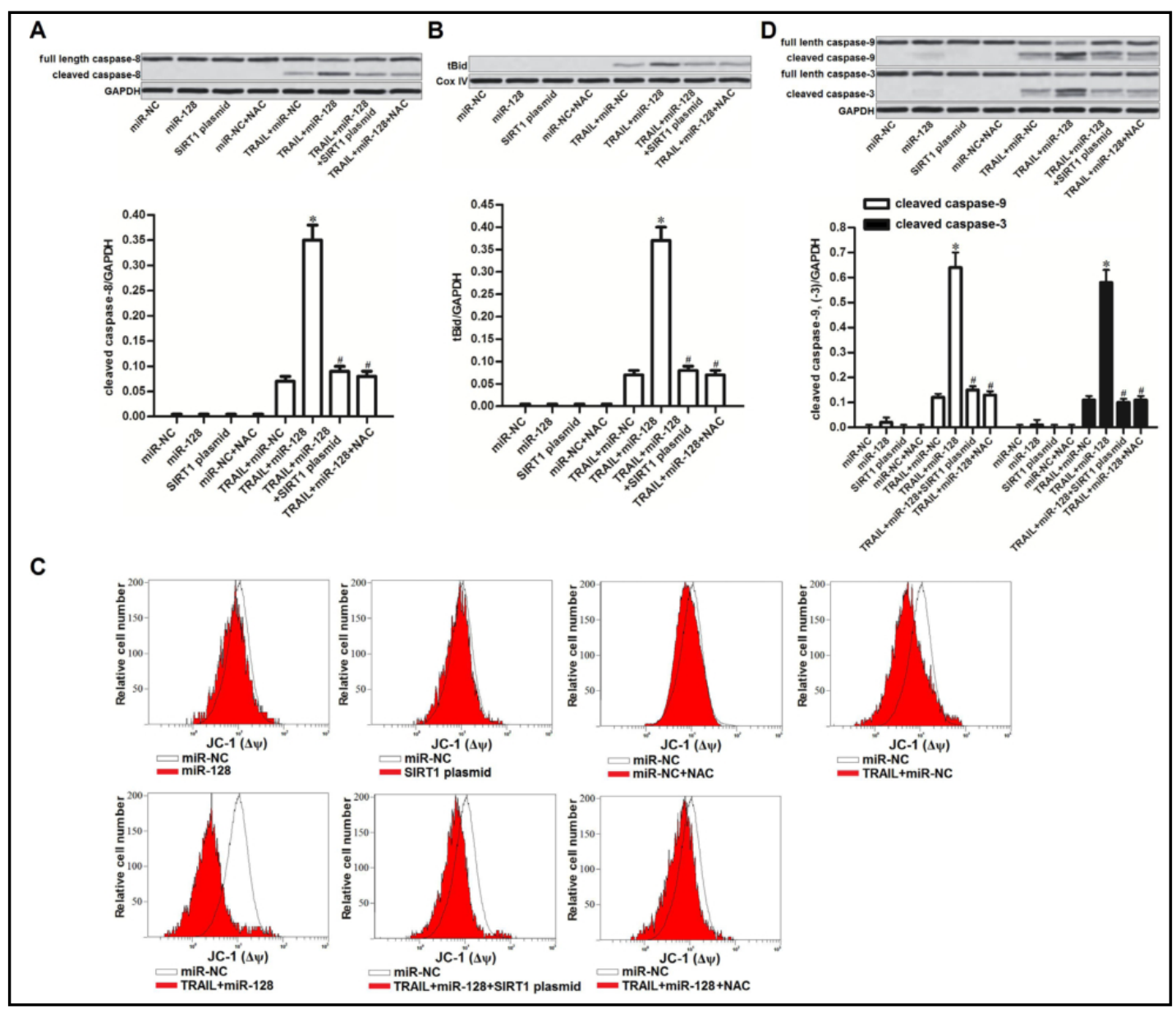

Fig. 7. Effect of miR-128 on the TRAIL-induced mitochondrial apoptosis pathway. A: Cleavage of caspase-8 in SW480 cells treated with TRAIL ( $5 \mathrm{ng} / \mathrm{mL}), \mathrm{miR}-128(50 \mathrm{pmol} / \mathrm{mL})$, SIRT1 plasmid $(2 \mu \mathrm{g} / \mathrm{mL})$, and NAC $(2 \mathrm{mM})$ was detected by western blot analysis. ${ }^{*} \mathrm{P}<0.05$ vs. TRAIL + miR-NC group; ${ }^{\text {P }}<0.05$ vs. TRAIL + miR128 group. B: After the isolation of mitochondria, the translocation of tBid to the mitochondria in SW480 cells treated with TRAIL ( $5 \mathrm{ng} / \mathrm{mL})$, miR-128 (50 pmol/mL), SIRT1 plasmid (2 $\mu \mathrm{g} / \mathrm{mL})$, and NAC (2 mM) was detected by western blot analysis. ${ }^{*} \mathrm{P}<0.05$ vs. TRAIL + miR-NC group; ${ }^{~} \mathrm{P}<0.05$ vs. TRAIL + miR-128 group. C: Mitochondrial membrane potential $(\Delta \varphi)$ of SW480 cells treated with TRAIL ( $5 \mathrm{ng} / \mathrm{mL})$, miR-128 (50 pmol/ $\mathrm{mL})$, SIRT1 plasmid ( $2 \mu \mathrm{g} / \mathrm{mL})$, and NAC ( $2 \mathrm{mM})$ was measured by flow cytometry. D: Western blot analysis was performed to detect the cleavage of caspase- 9 and caspase-3 in SW480 cells treated with TRAIL (5 $\mathrm{ng} / \mathrm{mL}), \mathrm{miR}-128(50 \mathrm{pmol} / \mathrm{mL})$, SIRT1 plasmid $(2 \mu \mathrm{g} / \mathrm{mL})$, and NAC $(2 \mathrm{mM}) .{ }^{*} \mathrm{P}<0.05 \mathrm{vs}$. TRAIL $+\mathrm{miR}-\mathrm{NC}$ group; ${ }^{\mathrm{P}}<0.05$ vs. TRAIL + miR-128 group. 


\section{Cellular Physiology Cell Physiol Biochem 2018;49:2151-2162

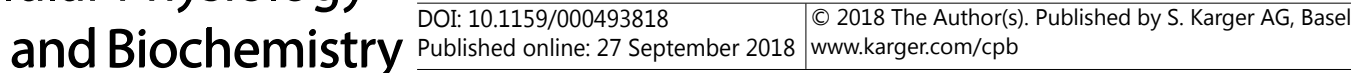 \\ Lian et al.: miR-128 Sensitizes CRC to TRAIL}

and miR-128 co-treated SW480 cells. This indicated that miR-128 targeted the SIRT1/ROS/ DR5 pathway to activate TRAIL signaling in CRC. Downstream of caspase-8 signaling, Bid is cleaved and translocates to the mitochondria in the form of tBid [20]. Our results showed that miR-128 significantly enhanced the translocation of tBid to mitochondria in TRAIL-treated SW480 cells (Fig. 7B). Subsequently, we found that co-treatment with miR-128 and TRAIL significantly enhanced the ability of TRAIL to decrease mitochondrial membrane potential $(\Delta \varphi)$ in SW480 cells (Fig. 7C). As a result of mitochondrial collapse in TRAIL and miR-128 co-treated SW480 cells, the mitochondrial apoptosis inducers caspase-9 and caspase-3 were found to be significantly activated (Fig. 7D). Taken together, we demonstrated that miR-128 promoted TRAIL-induced mitochondrial apoptosis through the SIRT1/ROS/DR5 pathway in CRC.

\section{Discussion}

miR-128 is considered to be a tumor suppressor that impedes tumor growth and metastasis in a variety of cancers [21-23]. Moreover, the aberrant expression of miRNAs has been demonstrated to be involved in the mechanisms of drug resistance in tumors. Among them, miR-128 is usually downregulated in cancer cells, which contributes to their resistance to many antineoplastic drugs such as cisplatin, doxorubicin, and gefitinib [24-26]. However, the potential role of miR-128 in TRAIL treatment in CRC is still unclear. In the present study, we observed a significant downregulation of miR-128 expression in tumor tissues from patients with CRC and cell lines. Consistent with the above reports, we demonstrated that miR-128 is a potential tumor suppressor in CRC. More importantly, the present study showed that the aberrant expression of miR-128 was associated with TRAIL resistance in CRC. The recovery of miR-128 expression was found to increase TRAIL cytotoxicity against CRC cells.

In the TRAIL-dependent cell death signaling pathway, TRAIL couples with DR5 on the surface of cancer cells to form the death-inducing signaling complex (DISC). DISC cleaves its substrate of pro-caspase-8 to convert it into its active form [27-29]. Subsequently, activated caspase- 8 acts upon Bid to convert it into tBid, which is a bridging element between death receptor signaling and mitochondrial apoptosis [30,31]. Following the translocation of tBid into mitochondria, the outer membrane pore is opened and mitochondrial membrane potential $(\Delta \varphi)$ collapses. At the terminus of the TRAIL signaling pathway, caspase- 9 and its substrate caspase-3 are activated, which causes apoptotic cell death in cancers [32, 33]. In this study, we found that the combination of miR-128 with TRAIL induced a significant upregulation of DR5 in CRC cells. However, miR-128 single treatment could not increase DR5 expression. Thus, there must be some other indirect pathways by which miR-128 promotes DR5 expression and activates TRAIL signaling.

SIRT1, a cellular histone deacetylase, is usually overexpressed in multiple human cancers. Previous reports indicate that SIRT1 is a potential oncogene that promotes tumor progression and induces drug resistance $[34,35]$. High levels of SIRT1 in cancer cells increase the expression of superoxide dismutase, which is a key cellular antioxidant, and thus decreases the generation of ROS, which promote apoptosis through a variety of pathways [36, 37]. In the TRAIL signaling pathway, the increased generation of ROS upregulates DR5 expression and thus enhances TRAIL-induced apoptosis in cancer cells [38-40]. These reports suggest a potential strategy for TRAIL sensitization through the SIRT1/ROS/DR5 pathway.

In this study, we explored whether SIRT1 was a direct target of miR-128 in CRC cells. The recovery of miR-128 expression upregulated the expression of SIRT1, and thus promoted the TRAIL-induced generation of ROS in CRC cells. Although miR-128 could not upregulate DR5 directly, the combination of miR-128 with TRAIL was able to increase DR5 expression through the SIRT1/ROS/DR5 pathway in TRAIL-treated CRC cells. As a result, the recovery of miR-128 expression increased the cellular level of DISC and subsequently enhanced the apoptotic signaling pathway in CRC cells. 


\section{Cellular Physiology Cell Physiol Biochem 2018;49:2151-2162 \begin{tabular}{l|l|l} 
and Biochemistry Published online: 27 September 2018 & $\begin{array}{l}\text { (c) } 2018 \text { The Author(s). Published by S. Karger AG, Basel } \\
\text { www.karger.com/cpb }\end{array}$ \\
\hline
\end{tabular}}

\section{Conclusion}

In summary, the findings of this study suggest that miR-128 sensitizes CRC to TRAILinduced apoptosis by targeting the SIRT1/ROS/DR5 pathway. The combination of miR-128 with TRAIL may represent a novel strategy for the efficacious treatment of CRC.

\section{Acknowledgements}

This work was supported by the National Natural Science Fund from the National Natural Science Foundation of China (Grant No. 81402367), Liaoning BaiQianWan Talents Program 2017 (No. B44), and Liaoning Clinical Research Center for Colorectal Cancer (Grant No. 2015225005).

\section{Disclosure Statement}

The authors declare no conflicts of interest.

\section{References}

1 Siegel RL, Miller KD, Jemal A: Cancer statistics, 2015. CA Cancer J Clin 2015;65:5-29.

-2 Manfredi S, Lepage C, Hatem C, Coatmeur O, Faivre J, Bouvier AM: Epidemiology and management of liver metastases from colorectal cancer. Ann Surg 2006;244:254-259.

3 Ciombor KK, Wu C, Goldberg RM: Recent therapeutic advances in the treatment of colorectal cancer. Annu Rev Med 2015;66:83-95.

4 Grem JL: Sequencing of treatment in advanced unresectable colorectal cancer. J Natl Compr Canc Netw 2013;Suppl 4:S28-37.

5 Marin JJ, Sanchez de Medina F, Castaño B, Bujanda L, Romero MR, Martinez-Augustin O, Moral-Avila RD, Briz O: Chemoprevention, chemotherapy, and chemoresistance in colorectal cancer. Drug Metab Rev 2012;44:148-172.

6 Huang L, Li TJ, Zhang JW, Liu S, Fu BS, Liu W: Neoadjuvant chemotherapy followed by surgery versus surgery alone for colorectal cancer: meta-analysis of randomized controlled trials. Medicine (Baltimore) 2014;93:e231.

-7 Sophonnithiprasert T, Nilwarangkoon S, Nakamura Y, Watanapokasin R: Goniothalamin enhances TRAILinduced apoptosis in colorectal cancer cells through DR5 upregulation and cFLIP downregulation. Int J Oncol 2015;47:2188-2196.

-8 Sun X, Li Y, Zheng M, Zuo W, Zheng W: MicroRNA-223 Increases the Sensitivity of Triple-Negative Breast Cancer Stem Cells to TRAIL-Induced Apoptosis by Targeting HAX-1. PLoS One 2016;11:e0162754.

-9 Xu C, Shi L, Chen W, Fang P, Li J, Jin L, Pan Z, Pan C: MiR-106b inhibitors sensitize TRAIL-induced apoptosis in hepatocellular carcinoma through increase of death receptor 4. Oncotarget 2017;8:41921-41931.

10 Walczak H, Miller RE, Ariail K, Gliniak B, Griffith TS, Kubin M, Chin W, Jones J, Woodward A, Le T, Smith C, Smolak P, Goodwin RG, Rauch CT, Schuh JC, Lynch DH: Tumoricidal activity of tumor necrosis factor-related apoptosis-inducing ligand in vivo. Nat Med 1999;5:157-163.

11 Li X, You M, Liu YJ, Ma L, Jin PP, Zhou R, Zhang ZX, Hua B, Ji XJ, Cheng XY, Yin F, Chen Y, Yin W: Reversal of the Apoptotic Resistance of Non-Small-Cell Lung Carcinoma towards TRAIL by Natural Product Toosendanin. Sci Rep 2017;7:42748.

12 Hwang JS, Lee HC, Oh SC, Lee DH, Kwon KH: Shogaol overcomes TRAIL resistance in colon cancer cells via inhibiting of survivin. Tumour Biol 2015;36:8819-8829.

-13 Bartel DP: MicroRNAs: genomics, biogenesis, mechanism, and function. Cell 2004;116:281-297. 


\section{Cellular Physiology Cell Physiol Biochem 2018;49:2151-2162 and Biochemistry \begin{tabular}{l|l} 
DOI: 10.1159/000493818 & (c) 2018 The Author(s). Published by S. Karger AG, Basel \\
www.karger.com/cpb
\end{tabular}

14 Calin GA, Sevignani C, Dumitru CD, Hyslop T, Noch E, Yendamuri S, Shimizu M, Rattan S, Bullrich F, Negrini M, Croce CM: Human microRNA genes are frequently located at fragile sites and genomic regions involved in cancers. Proc Natl Acad Sci U S A 2004;101:2999-3004.

15 Fonseca-Sanchéz MA, Pérez-Plasencia C, Fernández-Retana J, Arechaga-Ocampo E, Marchat LA, RodríguezCuevas S, Bautista-Piña V, Arellano-Anaya ZE, Flores-Pérez A, Diaz-Chávez J, López-Camarillo C: microRNA-18b is upregulated in breast cancer and modulates genes involved in cell migration. Oncol Rep 2013;30:2399-2410.

16 Huang G, Chen X, Cai Y, Wang X, Xing C: miR-20a-directed regulation of BID is associated with the TRAIL sensitivity in colorectal cancer. Oncol Rep 2017;37:571-578.

-17 Zhang R, Xu J, Zhao J, Bai J: Knockdown of miR-27a sensitizes colorectal cancer stem cells to TRAIL by promoting the formation of Apaf-1-caspase-9 complex. Oncotarget 2017;8:45213-45223.

18 Quintavalle C, Donnarumma E, Iaboni M, Roscigno G, Garofalo M, Romano G, Fiore D, De Marinis P, Croce CM, Condorelli G: Effect of miR-21 and miR-30b/c on TRAIL-induced apoptosis in glioma cells. Oncogene 2013;32:4001-4008.

19 Halasi M, Wang M, Chavan TS, Gaponenko V, Hay N, Gartel AL: ROS inhibitor N-acetyl-L-cysteine antagonizes the activity of proteasome inhibitors. Biochem J 2013;454:201-208.

20 Huang K, Zhang J, O’Neill KL, Gurumurthy CB, Quadros RM, Tu Y, Luo X: Cleavage by Caspase 8 and Mitochondrial Membrane Association Activate the BH3-only Protein Bid during TRAIL-induced Apoptosis. J Biol Chem 2016;291:11843-11851.

21 Zhou XU, Qi L, Tong S, Cui YU, Chen J, Huang T, Chen Z, Zu XB: miR-128 downregulation promotes growth and metastasis of bladder cancer cells and involves VEGF-C upregulation. Oncol Lett 2015;10:3183-3190.

22 Sun X, Li Y, Yu J, Pei H, Luo P, Zhang J: miR-128 modulates chemosensitivity and invasion of prostate cancer cells through targeting ZEB1. Jpn J Clin Oncol 2015;45:474-482.

-23 Huang CY, Huang XP, Zhu JY, Chen ZG, Li XJ, Zhang XH, Huang S, He JB, Lian F, Zhao YN, Wu GB: miR-128$3 p$ suppresses hepatocellular carcinoma proliferation by regulating PIK3R1 and is correlated with the prognosis of HCC patients. Oncol Rep 2015;33:2889-2898.

24 Li B, Chen H, Wu N, Zhang WJ, Shang LX: Deregulation of miR-128 in ovarian cancer promotes cisplatin resistance. Int J Gynecol Cancer 2014;24:1381-1388.

-25 Zhu Y, Yu F, Jiao Y, Feng J, Tang W, Yao H, Gong C, Chen J, Su F, Zhang Y, Song E: Reduced miR-128 in breast tumor-initiating cells induces chemotherapeutic resistance via Bmi-1 and ABCC5. Clin Cancer Res 2011;17:7105-7115.

26 Jiang J, Feng X, Zhou W, Wu Y, Yang Y: MiR-128 reverses the gefitinib resistance of the lung cancer stem cells by inhibiting the c-met/PI3K/AKT pathway. Oncotarget 2016;7:73188-73199.

27 Bellail AC, Tse MC, Song JH, Phuphanich S, Olson JJ, Sun SY, Hao C: DR5-mediated DISC controls caspase-8 cleavage and initiation of apoptosis in human glioblastomas. J Cell Mol Med 2010;14:1303-1317.

-28 Fulda S, Debatin KM: Extrinsic versus intrinsic apoptosis pathways in anticancer chemotherapy. Oncogene 2006;25:4798-4811.

29 Salvesen GS, Walsh CM: Functions of caspase 8: the identified and the mysterious. Semin Immunol 2014;26:246-252.

-30 Li H, Zhu H, Xu CJ, Yuan J: Cleavage of BID by caspase 8 mediates the mitochondrial damage in the Fas pathway of apoptosis. Cell 1998;94:491-501.

-31 Billen LP, Shamas-Din A, Andrews DW: Bid: a Bax-like BH3 protein. Oncogene 2008;Suppl 1:S93-104.

-32 Wei MC, Lindsten T, Mootha VK, Weiler S, Gross A, Ashiya M, Thompson CB, Korsmeyer SJ: tBID, a membrane-targeted death ligand, oligomerizes BAK to release cytochrome c. Genes Dev 2000;14:20602071.

33 Naghdi S, Várnai P, Hajnóczky G: Motifs of VDAC2 required for mitochondrial Bak import and tBid-induced apoptosis. Proc Natl Acad Sci U S A 2015;112:E5590-5599.

-34 Elangovan S, Ramachandran S, Venkatesan N, Ananth S, Gnana-Prakasam JP, Martin PM, Browning DD, Schoenlein PV, Prasad PD, Ganapathy V, Thangaraju M: SIRT1 is essential for oncogenic signaling by estrogen/estrogen receptor $\alpha$ in breast cancer. Cancer Res 2011;71:6654-6664.

-35 Bae HJ, Noh JH, Kim JK, Eun JW, Jung KH, Kim MG, Chang YG, Shen Q, Kim SJ, Park WS, Lee JY, Nam SW: MicroRNA-29c functions as a tumor suppressor by direct targeting oncogenic SIRT1 in hepatocellular carcinoma. Oncogene 2014;33:2557-2567. 


\section{Cellular Physiology Cell Physiol Biochem 2018;49:2151-2162 \begin{tabular}{ll|l} 
and Biochemistry & $\begin{array}{l}\text { DOI: 10.1159/000493818 } \\
\text { Published online: } 27 \text { September } 2018\end{array}$ & $\begin{array}{l}\text { 2018 The Author(s). Published by S. Karger AG, Basel } \\
\text { www.kam/cpb }\end{array}$ \\
\cline { 2 - 3 }
\end{tabular}

-36 H.-C. Chen, Y.-M. Jeng, R.-H. Yuan, H.-C. Hsu, Y.-L. Chen: SIRT1 promotes tumorigenesis and resistance to chemotherapy in hepatocellular carcinoma and its expression predicts poor prognosis, Ann. Surg. Oncol 2011;19:2011-2019.

37 Jian KL, Zhang C, Shang ZC, Yang L, Kong LY: Eucalrobusone C suppresses cell proliferation and induces ROS-dependent mitochondrial apoptosis via the p38 MAPK pathway in hepatocellular carcinoma cells. Phytomedicine 2017;25:71-82.

-38 Park EJ, Choi KS, Yoo YH, Kwon TK: Nutlin-3, a small-molecule MDM2 inhibitor, sensitizes Caki cells to TRAIL-induced apoptosis through p53-mediated PUMA upregulation and ROS-mediated DR5 upregulation. Anticancer Drugs 2013;24:260-269.

39 Jayasooriya RG, Choi YH, Hyun JW, Kim GY: Camptothecin sensitizes human hepatoma Hep3B cells to TRAIL-mediated apoptosis via ROS-dependent death receptor 5 upregulation with the involvement of MAPKs. Environ Toxicol Pharmacol 2014;38:959-967.

-40 Tse AK, Cao HH, Cheng CY, Kwan HY, Yu H, Fong WF, Yu ZL: Indomethacin sensitizes TRAIL-resistant melanoma cells to TRAIL-induced apoptosis through ROS-mediated upregulation of death receptor 5 and downregulation of survivin. J Invest Dermatol 2014;134:1397-1407. 